\section{ENSINAR GEOMETRIA NOS PRIMEIROS ANOS DO ENSINO FUNDAMENTAL: O QUE REVELAM PROFESSORAS ALFABETIZADORAS?}

\section{TEACHING GEOMETRY IN THE FIRST YEARS OF FUNDAMENTAL EDUCATION: WHAT DO LITERACY TEACHERS REVEAL?}

Américo Junior Nunes da Silva ${ }^{1, *}$ / Ana Maria Porto Nascimento ${ }^{2} /$ Solange Fernandes Maia Pereira ${ }^{1}$

\section{INTRODUÇÃO}

Este trabalho apresenta resultados iniciais de uma pesquisa com turmas do $1^{\circ}$ e $2^{\circ}$ ano do Ensino Fundamental, turmas que fazem parte do Ciclo de Alfabetização, como definido no Documento Curricular Referencial da Bahia para Educação Infantil e Ensino Fundamental, Bahia (2019). Interessa-nos melhor conhecer o processo de alfabetização matemática que "é entendida como um instrumento para a leitura do mundo, uma perspectiva que supera a simples decodificação dos números e a resolução das quatro operações básicas" (BRASIL, 2014, p. 5).

Nesta etapa inicial da pesquisa objetivou-se "identificar o que compreendem professoras alfabetizadoras sobre Geometria; de que forma o seu ensino está sendo desenvolvido e o que esperam aprender em um espaço de estudo constituído na escola". Pretende-se, na continuidade do trabalho e com as indicações da pesquisa em andamento, planejar e desenvolver, junto com as alfabetizadoras, propostas para explorar os conceitos geométricos que constituem a Unidade Temática de Geometria no Ciclo de Alfabetização.
${ }^{1}$ Universidade do Estado da Bahia - UNEB, Senhor do Bonfim, Bahia - Brasil.

${ }^{2}$ Universidade Federal do Oeste da Bahia - UNEB, Barreiras, Bahia - Brasil.

${ }^{3}$ Universidade do Estado da Bahia - UNEB, Paulo Afonso, Bahia - Brasil

*E-mail para correspondência: ajnunes@uneb.br

\section{RESUMO}

Este artigo é resultado de uma pesquisa qualitativa, do tipo estudo de caso, que abordou o ensino de Geometria no Ciclo de Alfabetização. Foram objetivos deste estudo identificar o que compreendem professoras alfabetizadoras sobre Geometria, de que forma o seu ensino está sendo desenvolvido e o que esperam aprender em um espaço de estudo constituído na escola. Os dados foram produzidos a partir da realização de uma entrevista com um grupo de cinco professoras. Para a análise dos dados optou-se pela Análise de Conteúdo. Os conteúdos produzidos pelas professoras alfabetizadoras indicaram que a realidade de não aprendizagem dos conceitos geométricos e do consequente ensino inadequado destes conceitos ainda é uma realidade que inquieta e que instiga os estudiosos em Educação Matemática. Pretende-se, com essa atividade piloto, ampliar e buscar representativos da rede municipal de ensino, inclusive constituindo a escola enquanto espaço de pesquisa e formação.

Palavras-chave: Ensino de Geometria. Alfabetização. Escola. Formação de Professores.

\section{ABSTRACT}

This article is the result of a qualitative research, of the case study type, which addressed the teaching of Geometry in the Literacy Cycle. The objectives of this study were to identify what literacy teachers understand about Geometry, how their teaching is being developed and what they hope to learn in a study space established in the school. The data were produced from an interview with a group of five teachers. For the analysis of the data, Content Analysis was chosen. The contents produced by literacy teachers indicated that the reality of not learning geometric concepts and the consequent inadequate teaching of these concepts is still a reality that worries and instigates scholars in Mathematics Education. The aim of this pilot activity is to expand and search for representatives of the municipal education network, including establishing the school as a space for research and training.

Keywords: Geometry teaching. Literacy. School. Teacher training.

Submetido em: 2 de abr. 2019

Aceito em: 11 de nov. 2020 
O trabalho como formadores de professores nos cursos de formação inicial, Licenciatura em Pedagogia e em Matemática, possibilitou, além de ministrar aulas nestes cursos, principalmente nos componentes curriculares da área de Educação Matemática, acompanhar Estágio Supervisionado e atuar em projetos de extensão e pesquisa promovidos pela Universidade de modo a observar o trabalho dos professores em escolas da rede municipal de ensino. $\mathrm{O}$ maior interesse pelas professoras alfabetizadoras 4 deve-se, como destacamos anteriormente, pela nossa imersão no espaço de formação inicial de professores que ensinam Matemática e nossas vivências enquanto formadores e coordenadores no Pró-Letramento e no Pacto Nacional pela Alfabetização na Idade Certa (PNAIC).

Nesses contextos foi possível constatar que a área de Matemática, sua aprendizagem e seu ensino, ainda provocam desconforto no fazer pedagógico da sala de aula. Inúmeras pesquisas, como as desenvolvidas por Pavanello (1989), Nacarato (2003), Marchesin (2007), Moraes (2008), Carvalho (2010), Biani (2013), Passos e Nacarato (2014), Nacarato, Mengali e Passos (2014), Nascimento (2016) e Silva e Passos (2020), voltadas para os anos iniciais, sinalizam problemas que ainda precisam ser superados, principalmente em relação ao ensino e a aprendizagem da Geometria. As professoras dos anos iniciais, muitas vezes, não se sentem à vontade para lidar com os conteúdos de Matemática que constituem o currículo dos anos iniciais do Ensino Fundamental (MANDARINO, 2009).

${ }^{4}$ Optamos, para a construção desse texto, pela utilização do termo em feminino, por possuirmos uma amostra formada apenas por sujeitos do sexo feminino.
Em relação a esse desconforto, nos parece oportuno destacar que os cursos de formação inicial para atuar no ciclo de alfabetização, especificamente, hoje, os cursos de Pedagogia, apresentam deficiências, sobretudo, na construção da identidade de professora que ensina matemática, como asseveram Silva e Passos (2020). Muitas das futuras educadoras não conseguem se perceber ensinando Matemática e isso implica no processo de ensino e aprendizagem, uma vez que elas, ainda segundo os autores anteriormente referenciados, constroem imagens, inúmeras vezes negativas, antes e durante a formação inicial, que influenciam os estudantes em processo de alfabetização e em toda vida escolar.

Nacarato, Mengali e Passos (2014) e Silva e Passos (2020), sinalizam que as experiências de vida e o contato estabelecido com outros professores, mesmo antes de iniciar o processo formativo para a docência em cursos de formação inicial, constituem referência de prática profissional. Cabe, nesses casos, aos cursos, apresentarem novos repertórios, metodologias e outras práticas, que permitam a essas futuras professoras (re)pensarem e (re)significarem sua ação pedagógica com a Matemática.

Ainda segundo Passos e Nacarato (2014, p. 1147)

O ensino de Geometria na Educação Básica talvez seja o tema que mais mereceu estudos e pesquisas no final do século $\mathrm{XX}$. Depois de longo período de abandono, voltou a compor, de forma mais integrada à maioria dos livros didáticos de Matemática. Contudo, ainda não ocorreu o avanço esperado. $\mathrm{O}$ abandono, problemático no Ensino Fundamental I, se torna maior em se tratando do ciclo de alfabetização. Há uma forte tendência nesse ciclo de se colocar a ênfase na alfabetização da língua materna, desconsiderando tratar-se de um processo mais amplo que abrange todas as áreas do conhecimento.

Em nossos contatos com os professores em diferentes espaços de formação, quando se questiona quais os conteúdos seriam mais importantes para serem explorados em oficinas ou cursos, a Geometria aparece acompanhada da expressão "não aprendi isso". Isso justifica a nossa preocupação em aprofundar estudos nesse campo da Educação Matemática: a aprendizagem e o ensino de Geometria no Ciclo de Alfabetização. E assim apresenta-se esse estudo inicial que será dividido em quatro partes: i) a Geometria como área de conhecimento e como objeto de ensino; ii) percurso metodológico; iii) o que revelam as professoras alfabetizadoras sobre a sua aprendizagem dos conceitos geométricos e sobre o ensino; iv) e, por último, as considerações e encaminhamentos da pesquisa.

\section{A GEOMETRIA COMO ÁREA DE CONHECIMENTO E COMO OB- JETO DE ENSINO}

Compreendemos, respaldandose em Bahia (2019) e Nacarato e Passos (2014), a importância da Geometria na vida dos cidadãos porque ela contribui para o desenvolvimento cognitivo nos aspectos referentes à forma, dimensão e direção, e ainda, possibilita a construção de competências geométricas fundamentais ao sujeito nas atividades de localização, deslocamento, representações de objetos do mundo físico e espaços territoriais por meio de croquis, plantas baixas e mapas, reconhecimento e classificação de figuras geométricas e, ainda, subsidia a formalização de vários conhecimentos inseridos no campo da Matemática. "Uma das razões da importância da 
Geometria é sua presença constante em nosso dia a dia. Já nos primeiros meses de vida, as crianças iniciam-se no aprendizado dos movimentos e no reconhecimento dos objetos do espaço em seu redor" (CARVALHO E LIMA, 2010 , p. 135). O que evidencia a necessária exploração do campo geométrico, como já previsto por Bahia (2019).

Em nossas experiências de formação nos deparamos com situações onde os professores apresentaram dificuldades em realizar atividades que exigiam noções de orientação, habilidades de representação do espaço, classificação das figuras e sólidos geométricos, descrição, comparação e análise das figuras planas ou espaciais por características comuns. Diante deste contexto de dificuldade dos docentes diante dos conceitos geométricos, surgiu o questionamento: como garantir às crianças os direitos de aprendizagem na Geometria, propostos pelos Referenciais Curriculares da Bahia (BAHIA, 2019), se o professor que ensina Matemática nos anos iniciais não domina os conhecimentos elementares nessa área?

As dificuldades em aprender e ensinar os conceitos geométricos fazem parte de um contexto histórico onde os conteúdos de Geometria eram relegados as páginas finais dos livros didáticos e, muitas vezes, não era trabalhados. De acordo com Nacarato e Passos (2014), quando estes conteúdos, atendendo as indicações dos pesquisadores que defendem a necessidade do estímulo ao desenvolvimento do pensamento geométrico desde o início da escolarização, passaram a figurar de forma mais articulada durante as unidades letivas na maioria dos livros didáticos de Matemática, o tratamento didático-pedagógico ainda mostra-se inadequado porque o professor rara- mente se sente preparado para trabalhá-lo.

Neste contexto, ainda é possível observar que pouca atenção tem sido dada ao estudo da Geometria nas aulas de Matemática dos Anos Iniciais. As formações de professores na área de Geometria são insuficientes e, principalmente quando ocorrem fora da escola tornam-se, muitas vezes, improdutivas. Em alguns casos, quando propostas se concentram na ênfase ao reconhecimento de figuras e nas relações métricas de cálculos de medidas de lados, áreas, volumes, ou enfatizase uma visão "equivocada" de que as crianças necessitam serem guiadas por imagens bonitas. Concordamos com Biani (2013, p. 4) quando afirma que os professores que ensinam Matemática necessitam de espaços de troca de experiências que permitam "discutir, analisar práticas, argumentar, estudar, adquirir suporte teórico e metodológico" de modo a refletir sobre o seu trabalho e analisar a sua experiência e neste contexto formar o seu pensamento geométrico e ampliar o seu desenvolvimento profissional docente.

Esses espaços de troca que nos referimos anteriormente são importantes para a formação continuada do docente e, como revela Cerrillo (2001), precisam ser constituídos, também, dentro de seu próprio espaço de atuação profissional, em nosso caso na escola da Educação Básica. Ainda segundo o autor anteriormente referenciado, o comportamento do professor será moldado pelo seu espaço de trabalho, uma vez que se estimula a criatividade e se permite a autorreflexão sobre a ação. Infelizmente, muitos gestores não reconhecem esse papel e não criam espaços de reflexão e formação.

Por percebermos ser um termo importante para este texto, considera- mos oportuno conceituar o que entendemos por "formação continuada", uma vez que se trata de um objeto central desta investigação. Nessa direção, como sinaliza Silva (2018), percebemos a formação como um processo que se inicia durante a graduação e que se estende ao longo de sua vida acadêmica e profissional, dando uma ideia de continuum. Dessa forma, ainda concordando com o autor, acreditamos que as experiências formativas oportunizadas pela formação inicial deverão ser aprofundadas ao longo das experiências profissionais, e a escola é um espaço importante nesse movimento.

\section{PERCURSO METODOLÓGICO}

Pelo que propomos com essa pesquisa, é oportuno defini-la como sendo um estudo de caso, sobretudo pelo olhar a um ou poucos objetos, possibilitando o seu amplo e detalhado conhecimento (GIL, 2012); de caráter exploratório, por "proporcionar maior familiaridade com o problema, com vistas a torná-lo mais explícito [...]" (GIL, 2012, p. 41) e com abordagem qualitativa, sobretudo por ser uma "pesquisa da própria realidade para conhecê-la melhor e poder vir a atuar mais eficazmente sobre ela, transformando-a" (ANDRÉ, 2002, p. 33).

Para o percurso de produção de dados fizemos uso de entrevista, definida por Gil (2012, p. 109) “como a técnica em que o investigador se apresenta frente ao investigado e lhe formulam perguntas, com o objetivo de obtenção dos dados que interessam à investigação". A entrevista é, ainda segundo o autor, uma forma de interação social, uma forma de diálogo em que se busca produzir dados para a investigação, constituindo-se um instrumento adequado para a obtenção de 
informações acerca do que as pessoas "sabem, creem, esperam, sentem ou desejam, pretendem fazer, fazem ou fizeram, bem como acerca das suas explicações ou razões a respeito das coisas precedentes" (GIL, 2012, p. 109).

Os participantes dessa etapa inicial da pesquisa foram cinco professoras do Ciclo de Alfabetização, turmas de $1^{\circ}$ e $2^{\circ}$ ano do Ensino Fundamental, de uma escola pública da rede municipal de ensino, de um município situado no interior do Estado da Bahia. São todas Licenciadas em Pedagogia e atuam a mais de dez anos nos anos iniciais do Ensino Fundamental, constituindo-se, como destaca Huberman (2000), professoras experientes. Por uma questão ética não divulgaremos as identidades das participantes e usaremos os codinomes Rosa, Margarida, Tulipa, Camélia e Capitu para identificá-las.

Vale salientar que todos os cuidados éticos foram tomados, inclusive com todos assinando o Termo de Consentimento Livre e Esclarecido (TCLE). A entrevista foi realizada com elas em seu próprio espaço de atuação profissional. As perguntas, pensadas a nos possibilitar ampliar o olhar acerca do que objetivamos com esse estudo foram: (1) $\mathrm{O}$ que aprendi de Geometria na formação inicial? (2) $\mathrm{O}$ que ensino de Geometria no Ciclo de Alfabetização? (3) O que espero aprender sobre Geometria em um possível espaço de estudo constituído na escola? As respostas a essas questões irão direcionar a continuidade das ações de pesquisa.

Tendo em vista os conteúdos produzidos pelas professoras alfabetizadoras, quando das respostas apresentadas a entrevista, optamos pelo método da Análise de Conteúdo (AC). A esse método, como assevera Bardin (2009, p. 121), consiste um conjunto de técnicas de análise das comunicações que faz uso de procedimentos sistemáticos e objetivos de descrição do conteúdo da mensagem, organizado em torno de três polos: i) A préanálise; ii) A exploração do material; e iii) $\mathrm{O}$ tratamento dos resultados: a inferência e a interpretação. Explicaremos, a seguir, as etapas que constituíram essa análise.

A pré-análise, como destaca Bardin (2009), busca sistematizar as informações para que o pesquisador proceda às operações sucessivas de análise. Portanto, inicialmente, transcrevemos as entrevistas realizadas, criando o repertório que seria analisado. Após essa transcrição realizamos uma análise inicial, a pré-análise, que nos evidenciou indicadores que auxiliaram na interpretação final.

Após esse movimento de sistematização das informações, ainda orientados pela $\mathrm{AC}$, fizemos uma seleção para perceber o que de comum havia nas falas apresentadas pelas professoras alfabetizadoras no momento da entrevista. A recorrência de palavras, ou conteúdo produzido, funcionou como indicativo de semelhanças entre dados e ideias. Para marcar essa recorrência decidimos por usar três marcações: negrito, itálico e sublinhado, para evidenciar os conteúdos que se aproximam e agrupá-los em categorias de análise.

Destaquemos que, para esta pesquisa, tivemos como foco para direcionar a análise, bem como para a construção das interpretações, os objetivos propostos (identificar o que compreendem essas professoras alfabetizadoras sobre Geometria, de que forma o seu ensino está sendo desenvolvido e o que esperam aprender em um espaço de estudo constituído na escola).
O QUE REVELAM AS PROFESSORAS SOBRE A SUA APRENDIZAGEM DOS CONCEITOS GEOMÉTRICOS E O SEU MODO DE ENSINAR

Nessa sessão, analisaremos as respostas apresentadas pelas professoras alfabetizadoras as três questões feitas durante a entrevista: (1) O que aprendi de Geometria na formação inicial? (2) O que ensino de Geometria no Ciclo de Alfabetização? (3) O que espero aprender sobre Geometria em um possível espaço de estudo constituído na escola? Como já dissemos, por uma questão ética, usaremos os seguintes nomes para identificar as participantes: Rosa, Margarida, Tulipa, Camélia e Capitu.

$\mathrm{O}$ primeiro questionamento, "O que aprendi de Geometria na formação inicial?", foi pensado para permitir as professoras alfabetizadoras destacarem sobre as experiências tidas com esses conceitos durante o processo de formação inicial. Antes de adentrarmos necessariamente no que revelaram as professoras, pensamos ser oportuno conceituar o que entendemos, nesse momento, por formação inicial.

Tomamos por formação inicial, como destaca Silva (2018), o primeiro momento que prepara o sujeito para ingressar na profissão. Segundo as Diretrizes Nacionais para a Formação Inicial de Professores, Brasil (2001), essa formação precisa ser compreendida e vivenciada como espaço que ensine o futuro professor a aprender de modo contínuo e reflexivo, corroborando ao posto por Pimenta (1996), e explica que é nesse momento inicial de formação que se começa a ver-se como professor, constituindo a identidade docente.

Nessa direção, concordando ao que destaca Silva (2018), é importante 
considerar que ao chegarmos ao início da formação trazemos concepções sobre o que é ser professor, e essas concepções, muitas vezes, resultam das marcas deixadas pelas experiências de vida, positivas ou negativas. A formação inicial, como nos apresenta Oliveira (2011, p. 236), "não pode abdicar de oferecer espaço e tempo para a deliberação sobre o ensino que se deseja desenvolver, para a justificativa das opções feitas e análise do confronto das escolhas e da ação desenvolvida e das aprendizagens dos alunos".

Agora, após situar teoricamente a formação inicial, uma vez que esse entendimento é importante para analisarmos o que responderam as professoras alfabetizadoras, vejamos o que elas sinalizaram quanto ao questionamento inicial:

Rosa - "O que aprendi de Geometria foi muito pouco e superficial, apenas alguns conceitos básicos sobre a Geometria planas e não planas, como por exemplo: nome de algumas figuras e $\mathrm{o} \mathrm{n}^{\mathrm{o}}$ de lados. Muitos conteúdos não foram ensinados porque sempre ficavam para o fim do ano e nunca dava tempo de concluí-los".

Margarida - "Durante minha formação, aprendi somente o nome das formas geométricas planas e os sólidos geométrico, de forma descontextualizada e superficialmente o que vértices e arestas".

Tulipa - "Vi muito pouco. A escola pouco explorava. Geometria sempre estava no final do livro e normalmente não a concluímos".

Camélia - "Como já é de conhecimento de todos, Geometria era trabalhada somente no final do ano letivo e de forma muito superficial. Por isso, acredito que de fato, só aprendi as formas geométricas".

Capitu - "Aprendi, basicamente, sobre formas geométricas planas, ponto e reta".
Fica evidente, nos excertos negritados acima, que todas as professoras alfabetizadoras, corroborando ao que destacou Passos e Nacarato (2014), destacam a superficialidade com que os conteúdos de Geometria são apresentados durante a formação inicial. As palavras "muito pouco", "superficial", "somente", e "basicamente", foram usadas e marcam bem como se dava esse ensino. Algumas das alfabetizadoras reportaram-se, também, a vida escolar e destacaram a forma como acontecia, ou não, esse ensino. As professoras Rosa e Tulipa, por exemplo, relatam que a "Geometria sempre estava no final do livro" e "nunca dava tempo [de concluir]". Outro ponto que merece destaque, e que foi sinalizado por Margarida, é a descontextualização com que se ensinava Geometria, diferentemente ao que apresentamos quanto à ligação desses conceitos ao dia a dia das crianças em processo de alfabetização (CARVALHO e LIMA, 2010).

As respostas apresentadas pelas professoras nos fazem refletir sobre duas coisas que estão diretamente relacionadas. A primeira delas diz respeito à formação inicial de professores que ensinam Matemática, em nosso caso o curso de Pedagogia, que não consegue, muitas vezes, romper com as dificuldades que os futuros professores alfabetizadores apresentam quanto ao tratar os conceitos matemáticos; e para sustentar essa afirmação fazemos uso de pesquisas, como as realizadas por Almeida (2009) e Trujillo (2009), que sinalizaram que muitos estudantes concluem o curso de Pedagogia sem o conhecimento matemático necessário para a prática docente. A segunda questão refere-se ao abandono do ensino da Geometria que, por muito tempo, deixou marcas que reverberam até hoje na vida e prática docente. A superficialidade no tratar os conceitos geométricos fazem os professores se sentirem desconfortáveis, corroborando ao que apresentou Mandarino (2009), uma vez que não se percebem preparados para tal ensino (PASSOS e NACARATO, 2014), como veremos no parágrafo a seguir.

Em relação ao segundo questionamento, "O que ensino de Geometria no Ciclo de alfabetização?", vale destacar alguns excertos apresentados pelas alfabetizadoras. Rosa, por exemplo, destaca que "o que eu ensino de Geometria no ciclo de alfabetização também são conceitos básicos relacionados às formas geométricas, e ainda assim de forma superficial, pois me falta conhecimento suficiente e segurança para ir além do básico". Camélia e Capitu, assim como Rosa, sinalizaram dificuldades quanto ao trabalhar os conceitos geométricos por não terem "domínio do conteúdo".

Muitas vezes, os limitadores impostos pela formação inicial, como nos apresentaram as professoras em suas respostas, não conseguem ser rompidos facilmente, principalmente, quando não se institui na escola, corroborando ao que apresentou Cerrillo (2001), um espaço de formação e reflexão sobre as diferentes problemáticas postas pela prática docente. Quando o espaço escolar não é pensado nessa perspectiva, cabe ao docente, de sua forma e em seu tempo, ressignificar essas dificuldades. $\mathrm{O}$ que percebemos, em muitas situações, como assevera Giroux (1988), é que as instituições de formação de professor e as escolas públicas se omitem em seu papel de educar os docentes como intelectuais.

No entanto, consideramos extremamente importante pontuar que algumas das marcas deixadas pela formação inicial são rompidas pelas 
professoras. Nesse sentido, Margarida, por exemplo, que sinalizou ter vivido um ensino de Geometria descontextualizado, apresenta uma prática pedagógica onde ela tenta "contextualizar com objetos, como cilindro, a mesma forma da lata de óleo e leite condensado [...]". Porém, nos preocupa o domínio dos conceitos geométricos, uma vez que é difícil ensinar aquilo que não se sabe. Tulipa também tenta "relacionar algumas formas no cotidiano, perceber a Geometria como ponto chave para diversas constituições na sociedade, como construção civil, tecidos, arte, alimentos".

Referindo-se ao terceiro questionamento, "o que espero aprender sobre Geometria em um possível espaço de estudo constituído na escola?", fica evidente pelas professoras alfabetizadoras, a necessidade de "aprofundar os conteúdos a serem ensinados no ciclo de alfabetização”. As professoras Rosa, Tulipa e Camélia, por exemplo, reforçam, mais uma vez, a fragilidade com que esses conceitos foram trabalhados e apresentam a necessidade de superá-la, ao tempo que veem o interesse em "avançarem nos estudos", algo que é desejo também expresso pelas professoras Capitu e Margarida. Margarida ainda sinaliza a importância de se trabalhar esses conceitos de forma lúdica e contextualizada.

\section{CONSIDERAÇÕES E ENCAMI- NHAMENTOS DA PESQUISA}

Os depoimentos das professoras revelam uma realidade que vem sendo estudada há vários anos pelos pesquisadores da área de Educação Matemática: as dificuldades dos professores que ensinam Matemática nos anos iniciais do Ensino Fundamental em trabalharem os conceitos geométricos. Como nos mostraram as falas das pro- fessoras alfabetizadoras, até aqui analisadas, essa ainda é uma questão a se investigar. Os conteúdos produzidos deste pequeno grupo representativo em termos locais confirmaram as nossas inquietações e reforçaram o nosso desejo de estender esses questionamentos a outras escolas da rede municipal e, ao mesmo tempo, iniciar junto a esse pequeno grupo, estudos, discussões, elaboração, desenvolvimento e avaliação de sequências didáticas para explorar os conceitos geométricos.

Pretende-se ampliar essa pesquisa e delinear ações que levem em conta as reais necessidades de formação continuada das professoras e que, preferencialmente, os grupos de estudo e discussão aconteçam no local de trabalho e reúna profissionais da escola e os que atuam na universidade, inclusive estudantes da licenciatura em Matemática e em Pedagogia. Nossa intenção, portanto, é constituir a escola enquanto espaço importante de formação continuada, que tem nas práticas docentes das participantes e nas diversas problemáticas postas por elas de suas próprias realidades as questões necessárias para reflexão.

Especificamente, quanto ao ensino de Geometria, constatou-se que as necessárias mudanças, indicadas pelos pesquisadores citados neste texto, entre outros, ainda não aconteceram de forma adequada e não atendem as exigências dos mais atuais programas de melhoria da Educação Básica, principalmente no Ciclo de Alfabetização. Os resultados apontam que uma proposta de pesquisa e formação com o foco no ensino e na aprendizagem de Geometria é ainda pertinente e pode vir a atender aos anseios das professoras.

\section{REFERÊNCIAS}

ALMEIDA, M. B. A formação inicial de professores no curso de Pedagogia: constatações sobre a formação matemática para a docência nas séries iniciais do Ensino Fundamental. 2009. 177 f. Dissertação (Mestrado acadêmico em Educação para a Ciência e a Matemática). Universidade Estadual de Maringá, Maringá, PR, 2009. Disponível em:

$<$ http://cienciaematematica.vivawebint er-

net.com.br/media/dissertacoes/ed33a2 1649fb701.pdf>. Acesso em: 04 jun. 2020.

ANDRÉ, M. E. D. Etnografia da prática escolar. 8. ed. Campinas: Papirus, 2002.

BAHIA. Documento Curricular Referencial da Bahia para Educação Infantil e Ensino Fundamental - Superintendência de Políticas para Educação Básica. União Nacional dos Dirigentes Municipais de Educação. Bahia Salvador: Secretaria da Educação, 2019.

Disponível em:

<http://escolas.educacao.ba.gov.br/orie ntacoescurricularesestaduais $>$. Acesso em: 04 jun. 2020.

BARDIN, L. Análise de conteúdo. Lisboa, Portugal; Edições 70, LDA, 2009.

BIANI, R. P. Considerações sobre a geometria nos anos iniciais do ensino fundamental. Ciências em Foco, v. 4, n. 1, 19 fev. 2013. Disponível em: <https://econtents.bc.unicamp.br/inpec /index.php/cef/article/view/9195>. Acesso em: 04 jun. 2020.

BRASIL. Parecer CNE/CP n ${ }^{\circ}$ 09, de 08 de maio de 2001. Institui as diretrizes curriculares nacionais para a formação de professores da educação básica, em nível superior, curso de licenciatura, de graduação plena. Brasília, DF, 2001. Disponível em: <http://portal.mec.gov.br/cne/arquivos/ pdf/009.pdf $>$. Acesso em: 04 jun. 2020. 
BRASIL. Pacto Nacional pela Alfabetização na Idade Certa. Ministério da Educação, Secretaria de Educação Básica, Diretoria de Apoio à Gestão Educacional. Brasília: MEC, SEB, 2014. Disponível em: < http://pacto.mec.gov.br/materiaislistagem/item/download/21_9945a2941359 afb9a5bc726869f697c5>. Acesso em: 04 jun. 2020.

CARVALHO, J. B. P.; LIMA, P. F. Escolha e uso do livro didático. In: Matemática: Ensino Fundamental. João Bosco Pitombeira Fernandes de Carvalho/coord. Brasília: Ministério da Educação, Secretaria de Educação Básica, 2010. (Coleção Explorando o Ensino, v. 17). Disponível em: $<$ http://educacaointegral.mec.gov.br/i ma-

ges/pdf/bibioteca/2011_matematica_ca pa.pdf>. Acesso em: 04 jun. 2020.

CERRILLO, Q. M. La escuela como espacio de trabajo para los profesores. In: MARCELO, C. La función docente. Madrid: Editorial Síntesis, 2001. p. 141-170.

GIL, A. C. Métodos e técnicas de pesquisa social. 5. ed. São Paulo: Atlas, 2012.

GIROUX, H. A escola crítica e a política cultural. Trad. Dogmar M. L. Zibas. São Paulo: Cortez, 1988.

HUBERMAN, M. O ciclo de vida profissional dos professores. In: Nóvoa, A. (Org.). Vida de professores. 2. ed. Porto, Portugal: Porto Ed. 2000. p. 31-61.

MARQUESIN, D. F. B. Práticas compartilhadas e a produção de narrativas sobre aulas de Geometria: o processo de desenvolvimento profissional de professores que ensinam Matemática. 242 f. 2007. Dissertação (Mestrado em Educação - Linha de Pesquisa: Matemática, cultura e práticas pedagógicas). Programa de Pós-Graduação Scricto Sensu em Educação. Itatiba, SP: Universidade São Francisco. Itati- ba. 2007. Disponível em: <https://www.usf.edu.br/publicacoes/d issertacoes.vm>. Acesso em: 04 jun. 2020 .

MORAES, J. M. Construção dos conceitos geométricos no contexto de formação inicial de professores dos anos iniciais do Ensino Fundamental. 206 f. 2008. Dissertação (Mestrado em Educação) Programa de PósGraduação em Educação, Universidade de Brasília - Faculdade de Educação. Brasília, DF, 2008. Disponível em: <

https://repositorio.unb.br/handle/10482 /1267>. Acesso em: 04 jun. 2020.

NACARATO, A. M; Passos, C. L. B. A Geometria nas séries iniciais: uma análise sob a perspectiva da prática pedagógica e da formação de professores. São Carlos: EdUFSCar, 151 p, 2003.

NACARATO, A. M; MENGALI, B. L. S.; PASSOS, C. L. B. A Matemática nos anos iniciais do Ensino Fundamental: tecendo fios do ensinar e do aprender. 2a. ed. Belo Horizonte: Autêntica, 2014.

NASCIMENTO, A. M. P. A construção coletiva de uma práxis emancipatória em alfabetização Matemática. 232p. 2016. Tese (Doutorado em Educação) Programa de Pós-Graduação em Educação, Universidade de Brasília - Faculdade de Educação. Brasília, DF, 2016. Disponível em: < https://repositorio.unb.br/handle/10482 /22789>. Acesso em: 04 jun. 2020.

OLIVEIRA, R. M. M. A. Narrativas de formação: Aspectos da trajetória como estudante e experiências de estágio. Interacções, Portugal, vol.7. nº18. 2011. p. 229-245. Disponível em: < https://revistas.rcaap.pt/interaccoes/arti cle/view/466/420>. Acesso em: 04 jun. 2020.

PAVANELLO, R. M. O abandono do ensino da Geometria: uma visão histórica. Campinas. 201 f. 1989. Dissertação (Mestrado em Educação) Progra- ma de Pós-Graduação em Educação, Universidade Estadual de Campinas. Campinas, SP, 1989. Disponível em: < http://repositorio.unicamp.br/handle/R EPOSIP/252057>. Acesso em: 04 jun. 2020.

PASSOS, C. L. B; NACARATO, A. M. O ensino de Geometria no ciclo de alfabetização: um olhar a partir da provinha Brasil. Educação Matemática Pesquisa, v. 16, p. 1147-1168, 2014. Disponível em:

$<$ https://revistas.pucsp.br/index.php/e mp/article/view/22016>. Acesso em: 04 jun. 2020.

PIMENTA, S. G. Formação de professores - saberes da docência e identidade do professor. Revista Faculdade de Educação, São Paulo, julho 1996. p. 72-89. Disponível em: <

http://www.revistas.usp.br/rfe/article/v iew/33579>. Acesso em: 04 jun. 2020.

SILVA, A. J. N. A ludicidade no laboratório: considerações sobre a formação do futuro professor de Matemática. Curitiba: Editora CRV, 2014.

SILVA, A. J. N. Querido diário... O que revelam as narrativas sobre ludicidade, formação e futura prática do professor que ensina(rá) Matemática nos Anos Iniciais. 348 f. 2018. Tese (Doutorado em Educação). Programa de Pós-Graduação em Educação. Universidade Federal de São Carlos. São Carlos, SP, 2018. Disponível em $<$ https://repositorio.ufscar.br/handle/uf scar/10923>. Acesso em: 04 jun. 2020.

SILVA, A. J. N.; PASSOS, C. L. B. Formação do professor que ensina Matemática, ludicidade e narrativas: o que se pesquisou no Brasil. REVISTA ELETRÔNICA DE EDUCAÇÃO (SÃO CARLOS), v. 14, p. 1-18, 2020. Disponível em: <

http://www.reveduc.ufscar.br/index.ph p/reveduc/article/viewFile/3631/992>. Acesso em: 04 jun. 2020.

TRUJILLO, W. A formação inicial e os conhecimentos do o que e do como ensinar matemática nos anos iniciais 
do ensino fundamental: encontros e desencontros. 230 f. 2009. Dissertação (Mestrado em Educação) - Universidade Federal de Mato Grosso, Cuiabá/MT, 2009. Disponível em:

<http://D:/Usuarios/Usuario/Download s/Waldiney_Trujillo.pdf $>$. Acesso em: 04 jun. 2020. 